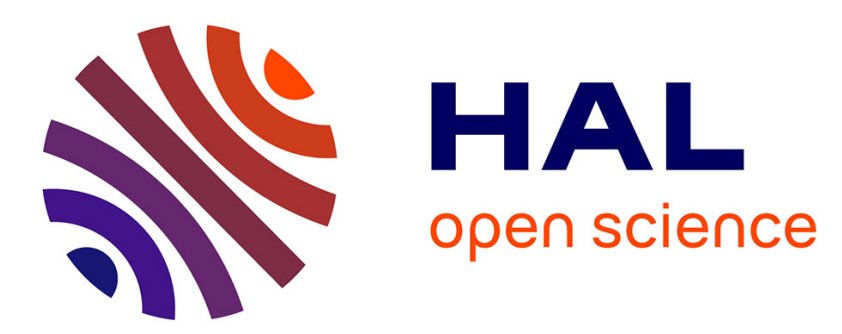

\title{
Facile synthesis and optical properties of extended TPA-Benzodifuran derivatives connected by cyano-vinylene junctions
}

Alexandre Faurie, Frédéric Gohier, Pierre Frère

\section{- To cite this version:}

Alexandre Faurie, Frédéric Gohier, Pierre Frère. Facile synthesis and optical properties of extended TPA-Benzodifuran derivatives connected by cyano-vinylene junctions. Dyes and Pigments, 2018, 154, pp.38-43. 10.1016/j.dyepig.2018.02.025 . hal-02564474

\section{HAL Id: hal-02564474 \\ https://univ-angers.hal.science/hal-02564474}

Submitted on 20 Sep 2021

HAL is a multi-disciplinary open access archive for the deposit and dissemination of scientific research documents, whether they are published or not. The documents may come from teaching and research institutions in France or abroad, or from public or private research centers.
L'archive ouverte pluridisciplinaire HAL, est destinée au dépôt et à la diffusion de documents scientifiques de niveau recherche, publiés ou non, émanant des établissements d'enseignement et de recherche français ou étrangers, des laboratoires publics ou privés.

\section{(c)(1)}

Distributed under a Creative Commons Attribution| 4.0 International License 


\title{
Facile synthesis and optical properties of extended TPA-Benzodifuran derivatives connected by cyano-vinylene junctions
}

\author{
Alexandre Faurie, Frédéric Gohier, Pierre Frère* \\ Université d'Angers, Moltech-Anjou UMR CNRS 6200, 2 Boulevard Lavoisier, 49045 Angers, France
}

\begin{abstract}
Two new conjugated molecules based on triphenylamine - benzo[1,2-b:4,5-b']difuran moieties and integrating cyanovinyl bonds have been synthesized by using the new benzodifuran-acetonitrile synthon, easily and rapidly prepared in two steps from 2,2'-(2,5-dihydroxy-1,4-phenylene)diacetic acid. The electronic properties of the molecules were analysed by UV-Vis absorption and emission spectroscopies and cyclic voltammetry. The potential use of the molecules as donor materials for photovoltaic conversion were evaluated in simple bilayer solar cells using $\mathrm{C} 60$ as the acceptor materials. The comparison between the two derivatives reveals that the extension of the conjugated system with the insertion of furan cycles leads to a narrowing band gap, a better emission property, a direct access to dication state and an enhancement of the photovoltaic characteristics.
\end{abstract}

\section{Introduction}

Furan-based conjugated derivatives represent a new investigated class of functional $\pi$ conjugated systems motivated by their potential applications as semiconducting materials in advanced optoelectronic devices [1,2]. Over the last decade several works brought out relevant benefits of the furan cycle for the development of conjugated materials [3]. The decrease in the aromaticity of the furan compared to the other aromatic rings constitutes an asset by allowing a better electronic delocalization along the conjugated chain. Moreover, it has been speculated that the insertion of furan cycles increased the rigidity and the planarity of the conjugated structures while maintaining a good solubility of the materials [1,4-7]. Finally, the relevant electronic properties and good processability of the materials make furan-based conjugated systems good candidates to be used as semiconductors in field effect transistors (OFET) [8-11] and organic photovoltaic cells (OPV) [12-15]. On the other hand, high interest of furan - based materials concerns their strong emissivity often observed both in solution and in the solid state [5,16-19]. Thus, the insertion of furan core in conjugated systems represents an efficient strategy for the development of luminogens that are promising for the development of organic electroluminescent diodes (OLED) [20,21].

As an extension of the studies about furan-based semiconductors, many works have been recently devoted to furan-fused systems and mainly to benzo[1,2-b:4,5-b']difuran units BDF) variously substituted on the benzenic core and/or on the furan units (Fig. 1) [22]. Derivatives integrating BDF units substituted on the furan positions often present high emission properties in the solid state that can be used for OLED applications [23-28]. BDF constitute also an attractive electron donor building block for the synthesis of donor -acceptor copolymers [29-36] or small molecules [37] used as donor materials in OPV. The synthetic approach of the BDF units often requests several delicate steps [38-41]. In recent contributions, we have shown that rapid synthetic approaches in two steps could be used for the synthesis of BDF-based small molecules [42-44]. In the continuation of this work, we report here on the rapid synthesis of the diacetonitrile-BDF derivative DiACN-BDF (Fig. 1) as a new building block to develop extended BDF materials via Knoevenagel condensations. Two examples of derivatives BDF1 and BDF2 combining BDF and triphenylamine (TPA) moieties have been synthesized and studied. The influence of the extension of the conjugated systems with furan units on the electronic properties of BDF1 and BDF2 is demonstrated.

\section{Experimental section}

\subsection{Synthesis}

2,2'-(2,5-dihydroxy-1,4-phenylene)diacetic acid $\mathbf{1}$ and TPA-CHO were purchased in Aldrich and used as received. Ylide 3 [45] and TPAFu-CHO [46] were prepared as described in the literature.

\subsubsection{Benzo[1,2-b:4,5-b']difuran-2,6(3H,7H)-dione 2}

A $10 \mathrm{~mL}$ tube equipped with a magnetic stirring bar was filled with $250 \mathrm{mg}$ of compound $1(1.1 \mathrm{mmol})$ and $0.5 \mathrm{~mL}$ of acetic anhydride in

\footnotetext{
* Corresponding author.

E-mail address: pierre.frere@univ-angers.fr (P. Frère).
} 
<smiles>[R]c1oc2c([R3])c3c([R])c([R])oc3c([R9])c2c1[R]</smiles><smiles>N#CCc1cc2cc3oc(CC#N)cc3cc2o1</smiles>

DIACN-BDF

Benzo[1,2-b:4,5-b']difuran<smiles></smiles>

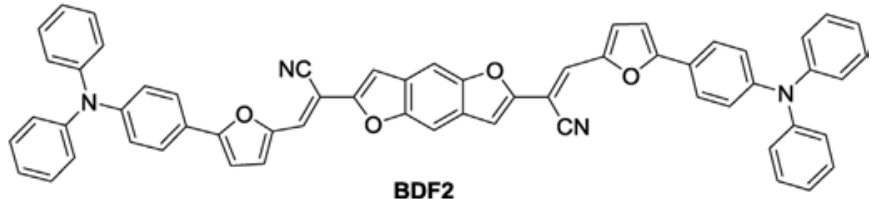

Fig. 1. Structures of benzodifuran derivatives.

$5 \mathrm{~mL}$ of toluene. The tube was sealed with a rubber cap and irradiated in CEM microwave Discover (P: $250 \mathrm{~W}, \mathrm{~T}=125^{\circ} \mathrm{C}, \mathrm{P}=5$ bars) for $15 \mathrm{~min}$. The mixture was cooled to room temperature and the solid was recovered by filtration and washed with $1 \mathrm{~mL}$ of toluene to give $188 \mathrm{mg}$ of $2(90 \%)$ as a white powder.

$\mathrm{Mp}=248^{\circ} \mathrm{C}$ (dec.). ${ }^{1} \mathrm{H}$ NMR $\left(\mathrm{CDCl}_{3}, 300 \mathrm{MHz}\right)$ ): $\delta 7.07$ (s, $\left.2 \mathrm{H}\right)$, 3.79 (s, 4H). ${ }^{13} \mathrm{C}$ NMR $\left.\left(\mathrm{CDCl}_{3}, 75 \mathrm{MHz}\right)\right): \delta 173.3,150.9,123.3,107.7$, 33.5. EI-MS: $190\left(\mathrm{M}^{+}\right)$[47].

\subsubsection{2,2'-(benzo[1,2-b:4,5-b']difuran-2,6diyl)diacetonitrile)}

DiACN$B D F$

In a sealed $10 \mathrm{~mL}$ microwave tube, a suspension of $140 \mathrm{mg}$ of 2 $(0.74 \mathrm{mmol})$ and $440 \mathrm{mg}$ of ylide $3(1.5 \mathrm{mmol})$ in $5 \mathrm{~mL}$ toluene was irradiated (P: $250 \mathrm{~W}, \mathrm{~T}: 125^{\circ} \mathrm{C}, \mathrm{P}: 5$ bars) for $20 \mathrm{~min}$. The mixture was cooled to room temperature and the solid was recovered by filtration and washed with $3 \times 4 \mathrm{~mL}$ of toluene to give $90 \mathrm{mg}$ of DiACN-BDF $(50 \%)$ as a grey powder.

Mp: $260{ }^{\circ} \mathrm{C}$ (dec.). ${ }^{1} \mathrm{H} \mathrm{NMR}\left(\mathrm{CDCl}_{3}, 300 \mathrm{MHz}\right)$ ): $\delta 7.57$ (s, $\left.2 \mathrm{H}\right), 6.81$ (s, $2 \mathrm{H}), 3.94(\mathrm{~s}, 4 \mathrm{H})$. The solubility of DiACN-BDF is too low for obtaining ${ }^{13} \mathrm{C}$ NMR. HRMS (EI) calcd for $\mathrm{C}_{14} \mathrm{H}_{8} \mathrm{~N}_{2} \mathrm{O}_{2}: 236.0586$, found: 236.0583 .

\subsection{General procedure for Knoevenagel condensations}

A mixture of $70 \mathrm{mg}$ of DiACN-BDF $(0.3 \mathrm{mmol})$ and $0.62 \mathrm{mmol}$ of aldehyde TPA-CHO $(170 \mathrm{mg})$ or TPA-Fu-CHO $(210 \mathrm{mg})$ and a catalytic amount of ${ }^{t} \mathrm{BuONa}(5 \mathrm{mg})$ was stirred in ethanol $(10 \mathrm{~mL})$ for $24 \mathrm{~h}$ at room temperature. The precipitate was separated by filtration and washed with $3 \times 5 \mathrm{~mL}$ of ethanol and dried in high vacuo giving coloured powder.

\subsubsection{BDF1}

$112 \mathrm{mg}$ of purple powder (50\% yield).Mp $>260{ }^{\circ} \mathrm{C}{ }^{1} \mathrm{H}$ NMR $\left(\mathrm{CDCl}_{3}, 300 \mathrm{MHz}\right): \delta 7.82(\mathrm{~d}, 4 \mathrm{H}, \mathrm{J}=8.9 \mathrm{~Hz}), 7.70(\mathrm{~s}, 2 \mathrm{H}), 7.57(\mathrm{~s}, 2 \mathrm{H})$ 7.36-7.31 (m, 8H), 7.19-7.15 (m, 12H), 7.06-7.02 (m, 6H). The solubility of BDF1 is too low for obtaining ${ }^{13} \mathrm{C}$ NMR. MALDI-TOF-MS: $\mathrm{m} /$ $z=746.3[\mathrm{M}]^{+}$. HRMS $\left(m / z, \mathrm{FAB}^{+}\right)$calcd for $\mathrm{C}_{52} \mathrm{H}_{34} \mathrm{~N}_{4} \mathrm{O}_{2}: 746.2682$, found: 746.2674 .

\subsubsection{BDF2}

$145 \mathrm{mg}$ of violet powder (55\% yield). $\mathrm{Mp}>260{ }^{\circ} \mathrm{C}{ }^{1} \mathrm{H}$ NMR $\left(\mathrm{CDCl}_{3}, 300 \mathrm{MHz}\right): \delta 7.71(\mathrm{~d}, 4 \mathrm{H}, \mathrm{J}=8.9 \mathrm{~Hz}), 7.54(\mathrm{~s}, 2 \mathrm{H}), 7.52(\mathrm{~s}, 2 \mathrm{H})$, 7.32-7.26 (m, 8H), 7.16-7.07 (m, $20 \mathrm{H}), 6.73$ (d, 2H, 3.8 Hz). The solubility of BDF2 is too low for obtaining ${ }^{13} \mathrm{C}$ NMR. MALDI-TOF-MS: $\mathrm{m} /$ $z=878.5[\mathrm{M}]^{+}$. HRMS $\left(m / z, \mathrm{FAB}^{+}\right)$calcd for $\mathrm{C}_{52} \mathrm{H}_{34} \mathrm{~N}_{4} \mathrm{O}_{2}: 878.2893$, found: 878.2889 .

\subsection{Preparation of the solar cells}

Indium-tin oxide coated glass slides of $24 \times 25 \times 1.1 \mathrm{~mm}$ with a sheet resistance of $\mathrm{RS}=10 \Omega / \mathrm{sq}$ were purchased from VisionTek Systems Ltd. The substrates were scrubbed using dishwashing soap before being cleaned by a series of ultrasonic treatments for $15 \mathrm{~min}$ in distilled water, acetone, and isopropanol. Once dried under a steam of nitrogen, a UV-ozone plasma treatment (UV/Ozone ProCleaner Plus, Bioforce Nanosciences) was performed for $15 \mathrm{~min}$. A filtered aqueous solution of poly(3,4-ethylenedioxy-thiophene)-poly(styrenesulfonate) (PEDOT:PSS; Clevios P VP. AI 4083) through a $0.45 \mu \mathrm{m} \mathrm{RC}$ membrane (Millex ${ }^{\circ}$ ) was spun-cast onto the patterned ITO surface at $5000 \mathrm{rpm}$ for $40 \mathrm{~s}$ before being baked at $115^{\circ} \mathrm{C}$ for $15 \mathrm{~min}$. The films of donor materials BDF1 and BDF2 were spun-cast from chloroform solutions containing $2 \mathrm{mg} / \mathrm{mL}$ of material then the cells were completed by the successive thermal deposition of $\mathrm{C}_{60}(30 \mathrm{~nm})$ and aluminum $(80 \mathrm{~nm})$ at a pressure of $10^{-6}$ Torr through a shadow mask defining two cells of $27 \mathrm{~mm}^{2}$ each. $\mathrm{J}$ vs $\mathrm{V}$ curves were recorded in the dark and under illumination using a Keithley 236 source-measure unit and a home-made acquisition program. The light source is an AM1.5 Solar Constant 575 PV simulator (Steuernagel Lichttecknik, equipped with a metal halogen lamp). The light intensity was measured by a broad-band power meter (13PEM001, Melles Griot). EQE was recorded under ambient atmosphere using a halogen lamp (Osram) with an Action Spectra Pro 150 monochromator, a lock-in amplifier (Perkin-Elmer 7225) and a S2281 photodiode (Hamamatsu).

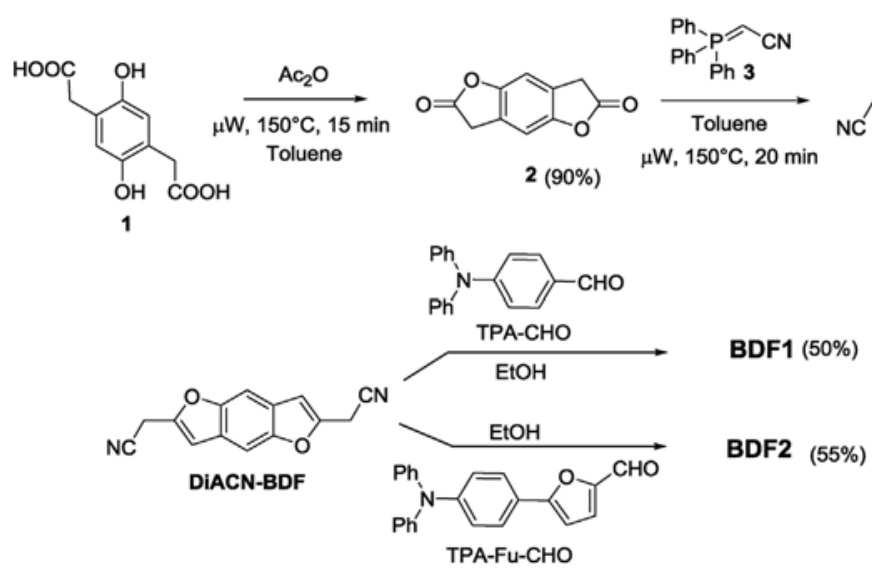

Scheme 1. Synthesis of compounds BDF1 and BDF2. 


\section{Results and discussion}

The synthetic pathway of BDF1 and BDF2 is presented in Scheme 1. The synthesis of the benzodifuran core is performed in two steps from the dihydroxyphenylene diacid $\mathbf{1}$. The first step corresponds to a double lactonization of $\mathbf{1}$ in presence of acetic anhydride. The product $\mathbf{2}$ is then engaged in a double Wittig reaction with the stabilized ylide 3 to give after rearrangement the diacetonitrile-BDF compound DiACN-BDF. These two successive reactions are carried out under microwave irradiation, which considerably reduces the reaction times. Thus, the first reaction is carried out in $15 \mathrm{~min}$ in $90 \%$ yield under microwave irradiation, against $5 \mathrm{~h}$ in $67 \%$ yield by using conventional heating [47]. The second step is performed in $20 \mathrm{~min}$ to give DiACN-BDF in $50 \%$ yield. The treatment of these two steps consists of a simple filtration of the reaction medium followed by a washing with ethanol of the obtained solids.

The target molecules are synthesized by a double Knoevenagel reaction carried out in ethanol at room temperature in presence of catalytic amount of ${ }^{t} \mathrm{BuONa}$ and by using a slight excess of the aldehydes TPA-CHO and TPA-Fu-CHO (2.1 equivalents). BDF1 and BDF2 are obtained by filtration then washing with ethanol in 50 and $55 \%$ yield respectively.

The electronic properties of the molecules BDF1-2 have been evaluated by theoretical calculations and analyzed by absorption and emission electronic spectroscopies and cyclic voltammetry. Theoretical and experimental data of the two compounds are gathered in Table 1.

Theroretical calculation were performed at the density functional theory level with the Gaussian package. Becke's three -parameter gradient corrected functional (B3LYP) with a polarized 6-31G $(\mathrm{d}, \mathrm{p})$ basis was used for full geometry optimization of all compounds. The contours of the HOMO and LUMO orbitals of BDF1 and BDF2 and a schematic evolution of their levels are shown in Fig. 2. The optimized configurations of BDF1 and BDF2 converge to a perfectly planar structure of the central core of the molecules while the external phenyl units show a torsion with the central BDF moiety. Thus, the HOMO and LUMO orbitals extend over the entire conjugated system located between the two nitrogen atoms of the TPA units without the contribution of the external phenyls. The insertion of the furan cycles in BDF2 leads to a decreasing of $0.3 \mathrm{eV}$ of the HOMO-LUMO gap concomitant both to a $0.11 \mathrm{eV}$ destabilization of the HOMO level and a $0.19 \mathrm{eV}$ stabilization of the LUMO level.

The cyclic voltammetry (CV) of compounds BDF1 and BDF2 was performed in reduction and oxidation. If in reduction the two compounds do not present any electroactivity until $-1.8 \mathrm{~V}$, in oxidation the CVs present two reversible oxidation waves (Fig. 3). The analysis of the first wave for BDF1 shows the presence of two close oxidation processes

Table 1

Theoretical HOMO and LUMO levels, experimental optical and electrochemical data.

\begin{tabular}{|c|c|c|c|c|c|c|c|}
\hline \multirow[t]{2}{*}{ Cpd } & \multicolumn{2}{|c|}{ Theoretical data ${ }^{\mathrm{a}}$} & \multicolumn{4}{|c|}{ Optical data } & \multirow{2}{*}{$\begin{array}{l}\text { Electrochemical } \\
\text { data }^{f}\end{array}$} \\
\hline & $\begin{array}{l}\text { LUMO (eV) } \\
\text { HOMO (eV) }\end{array}$ & $\begin{array}{l}\Delta \mathrm{E}_{\text {the }} \\
(\mathrm{eV})\end{array}$ & $\begin{array}{l}\lambda_{\max }^{b} \\
(\mathrm{~nm})\end{array}$ & $\begin{array}{l}\Delta \mathrm{E}_{\mathrm{opt}}{ }^{\mathrm{c}} \\
(\mathrm{eV})\end{array}$ & $\begin{array}{l}\lambda_{\mathrm{em}}{ }^{\mathrm{d}} \\
(\mathrm{nm})\end{array}$ & $\begin{array}{l}\Phi^{\mathrm{e}} \\
(\%)\end{array}$ & \\
\hline BDF1 & $\begin{array}{l}E_{L}=-2.29 \\
E_{H}=-4.86\end{array}$ & 2.57 & $\begin{array}{l}475 \\
499 \text { (sh) }\end{array}$ & 2.25 & 541 & 17 & $\begin{array}{l}\mathrm{E} 1=1.04\left(1 \mathrm{e}^{-}\right) \\
\mathrm{E} 2=1.15\left(1 \mathrm{e}^{-}\right) \\
\mathrm{E} 3=1.72\left(1 \mathrm{e}^{-}\right)\end{array}$ \\
\hline BDF2 & $\begin{array}{l}E_{L}=-2.48 \\
E_{H}=-4.75\end{array}$ & 2.27 & $\begin{array}{l}516 \\
547 \text { (sh) }\end{array}$ & 2.07 & 596 & 30 & $\begin{array}{l}\mathrm{E} 1=0.95\left(2 \mathrm{e}^{-}\right) \\
\mathrm{E} 2=1.37\left(1 \mathrm{e}^{-}\right)\end{array}$ \\
\hline
\end{tabular}

a Calculation performed at the B3LYP/6-31G(d,p) level of theory.

b $10^{-5} \mathrm{M}$ in THF.

c Optical band gap calculated from the edge of the absorption band.

d $10^{-5} \mathrm{M}$ in THF.

e Relative quantum yield evaluated according to the standard procedure by using Rhodamine $B$ in ethanol as standard solution $(\Phi s=0.97)$ [48]

${ }^{\mathrm{f}} 510^{-4} \mathrm{M}$ in $0.1 \mathrm{M} \mathrm{Bu} \mathrm{NPF}_{6}-\mathrm{CH}_{2} \mathrm{Cl}_{2}, 100 \mathrm{mV}$ s- 1 , Pt working electrode, ref SCE.
$E(\mathrm{eV})$

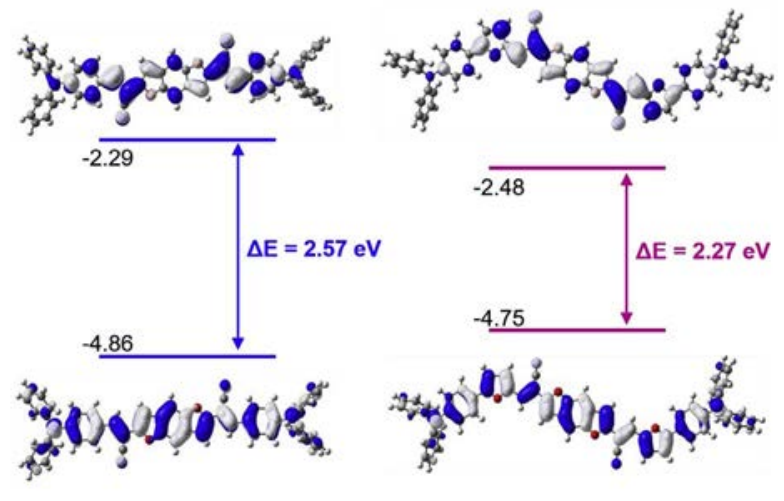

Fig. 2. Calculated HOMOs and LUMOs and energy levels for BDF1-2.
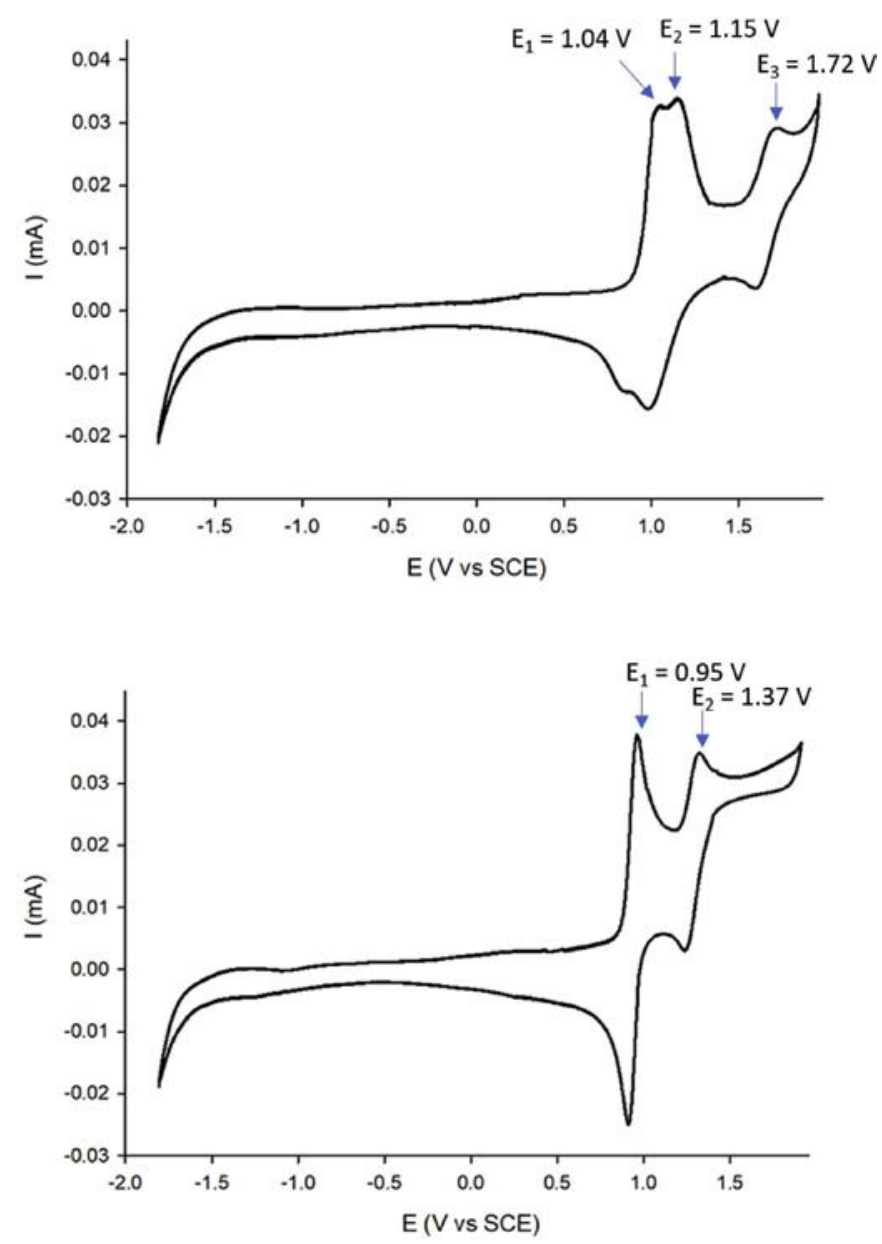

Fig. 3. $\mathrm{CV}$ traces of BDF1 (top) and BDF2 (bottom): $510^{-4} \mathrm{M}$ solution in $\mathrm{CH}_{2} \mathrm{Cl}_{2}$ containing $0.1 \mathrm{M} \mathrm{Bu}_{4} \mathrm{NPF}_{6}, \mathrm{v}=100 \mathrm{mVs}^{-1}$.

with peak potentials at $\mathrm{E} 1=1.04 \mathrm{~V}$ and $\mathrm{E} 2=1.15 \mathrm{~V}$, corresponding to the formation of radical cation then dication. The third oxidation wave with a peak potential at $\mathrm{E} 3=1.72 \mathrm{~V}$ is due to the formation of the trication radical. For compound BDF2, the extension of the conjugation with the two furan cycles favours the access to the polycationic state. Thus, the first oxidation wave at $\mathrm{E} 1=0.95 \mathrm{~V}$ corresponds to a direct access to the dication in a bi-electronic process while the oxidation to the trication radical is at $\mathrm{E} 2=1.37 \mathrm{~V}$. Recently similar results were obtained with extended benzofuran - thiophene-TPA derivatives [49], indicating that the central benzodifuran moiety allows a perfect 

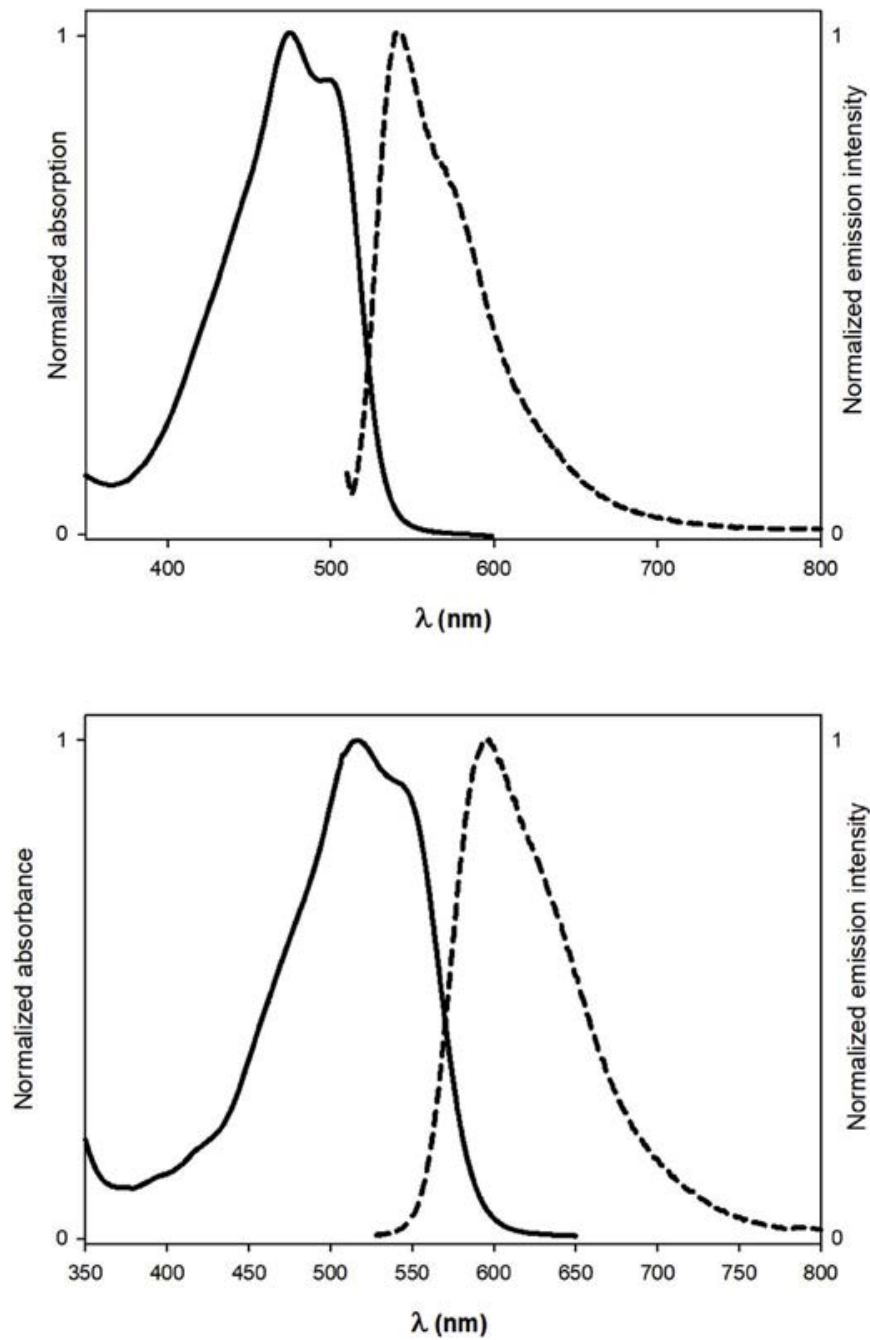

Fig. 4. Normalized UV-Vis absorption (solid line) and emission (dotted line) spectra of BDF1 (top) and BDF2 (bottom) in THF $\left(10^{-5} \mathrm{M}\right), \lambda_{\text {ex }}=490 \mathrm{~nm}$.

electronic delocalization. The experimental HOMO levels, calculated from the onset of the oxidation peak [50] $(-5.6 \mathrm{eV}$ for BDF1 and $-5.5 \mathrm{eV}$ for BDF2), follows the tendency given by the theoretical calculations with in particularly a small difference between the levels of BDF1 and BDF2 of only $0.1 \mathrm{eV}$.

The absorption and emission spectra of the compounds BDF1 and BDF2 were performed in tetrahydrofuran (THF) solution. Fig. 4 presents the normalized absorption and emission spectra of the compounds. The two compounds present a partially structured absorption bands corresponding to the $\pi-\pi^{*}$ transition with a $\lambda_{\max }$ and a shoulder at 475 and $499 \mathrm{~nm}$ for BDF1 and at 516 and $547 \mathrm{~nm}$ for BDF2. The structuration of the bands reflects the rigidity of the conjugated due to the central BDF moiety. In accordance with the theoretical calculations, the extension of the conjugation with the insertion of two furan cycles in BDF2 leads to a decreasing of the band gap from $2.25 \mathrm{eV}$ for BDF1 to $2.07 \mathrm{eV}$ for BDF2. The two compounds present an intense emission with maxima at $\lambda_{\mathrm{em}}=541 \mathrm{~nm}$ for BDF1 and at $596 \mathrm{~nm}$ for BDF2. The presence of the furan units enhances the emission properties with a quantum yield $\Phi$ of $30 \%$ for BDF2 and only of $17 \%$ for BDF1. Many linear conjugated systems built from cyano-vinyl units are known to present the aggregation induced enhancement emission (AIEE) phenomena [17,51,52]. Aggregates of BDF1 and BDF2 were formed by adding water to the THF solutions. As shown in Fig. S1 in the supporting information, the emission intensities decrease for becoming quasi null from $50 \%$ in volume of water. Thus, these two derivatives see
Table 2

Photovoltaic characteristics of PHJ cells based on donors BDF1 and BDF2 under 1.5AMsimulated solar illumination at $80 \mathrm{~mW} \mathrm{~cm}^{-2}$.

\begin{tabular}{lllllll}
\hline Cpd & $\mathrm{T}_{\text {annealing }}{ }^{\circ} \mathrm{C}$ & $\begin{array}{l}\mathrm{V}_{\mathrm{OC}}(\mathrm{V}) \\
\text { average }\end{array}$ & $\begin{array}{l}\mathrm{J}_{\mathrm{SC}}\left(\mathrm{mA} \mathrm{cm}^{-2}\right) \\
\text { average }\end{array}$ & $\begin{array}{l}\mathrm{FF}(\%) \\
\text { average }\end{array}$ & $\begin{array}{l}\text { PCE (\%) } \\
\text { average }\end{array}$ & $\begin{array}{l}\text { PCE (\%) } \\
\text { best }\end{array}$ \\
\hline \multirow{2}{*}{ BDF1 } & - & 0.65 & 2.20 & 33 & 0.59 & 0.63 \\
& 190 & 0.53 & 3.90 & 48 & 1.24 & 1.33 \\
BDF2 & - & 0.60 & 3.05 & 47 & 1.07 & 1.19 \\
& 180 & 0.60 & 4.25 & 50 & 1.59 & 1.65 \\
\hline
\end{tabular}

their fluorescence properties governed by the aggregation caused quenching (ACQ) effect, probably due to a strong propension of the central BDF unit to develop $\pi$ stacking in the solid state [22].

The potential of these extended BDF molecules as donor material in photovoltaic devices has been evaluated in basic bilayer planar heterojunction solar cells (PHJ) by using $\mathrm{C}_{60}$ as acceptor material. The use of $\mathrm{C}_{60}$ allows an easy fabrication of the cells by evaporation of the acceptor and a direct comparison of the performances of the cells prepared with the same methods from donor materials having analogue structures. The cells were prepared by spin-casting a chloroform solution of donor onto indium tin oxide (ITO) precoated with poly(3,4ethylenedioxythiophene):poly(styrenesulfonate) (PEDOT/PSS). Then a $30 \mathrm{~nm}$ layer of $\mathrm{C}_{60}$ were deposited by thermal evaporation under vacuum, followed by the deposition of an $80 \mathrm{~nm}$ aluminium electrode (27 $\mathrm{mm}^{2}$ of active area). Annealing tests of the films have been performed at different temperatures. Results are gathered in Table 2 and the current-voltage characteristics of the cells are presented in Fig. 5. Both compounds present a photovoltaic activity with average power conversion efficiencies (PCE) before annealing of 0.59 and $1.15 \%$ for BDF1 and BDF2 respectively. The cells show similar open circuit voltages $\left(\mathrm{V}_{\mathrm{OC}}\right)$ about $0.6-0.7 \mathrm{~V}$ in accordance with their close oxidation potentials. The more extended derivative BDF2 displays higher short circuit density $\left(\mathrm{J}_{\mathrm{SC}}=3.13 \mathrm{~mA} \mathrm{~cm}^{-2}\right)$ and above all a better fill factor $(\mathrm{FF}=50 \%)$ than BDF1 $\left(\mathrm{J}_{\mathrm{SC}}=2.21 \mathrm{~mA} \mathrm{~cm}^{-2}, \mathrm{FF}=34 \%\right)$. Both materials show a good stability to the heat treatment with annealing temperatures reaching $190{ }^{\circ} \mathrm{C}$ for obtaining optimal activities. For BDF1, the annealing makes it possible to double the average PCE to reach $1.28 \%$ (best PCE $1.33 \%$ ) by increasing the $\mathrm{J}_{\mathrm{SC}}\left(3.90 \mathrm{~mA} \mathrm{~cm}^{-2}\right)$ and the FF $(48 \%)$ while the $\mathrm{V}_{\mathrm{OC}}(0.53 \mathrm{~V})$ is decreasing. Concerning BDF2, the effects of annealing are less efficient giving an average PCE of $1.59 \%$ (best PCE $=1.65 \%$ ) with a rise of the $\mathrm{J}_{\mathrm{SC}}$ up to $4.25 \mathrm{~mA} \mathrm{~cm}^{-2}$ and a small enhancement of the FF to obtain $50 \%$ while the $\mathrm{V}_{\mathrm{OC}}$ stays stable at $0.60 \mathrm{~V}$. The performance of the cells with BDF2 are very close of the ones obtained with other analogue BDF materials [44]. The external

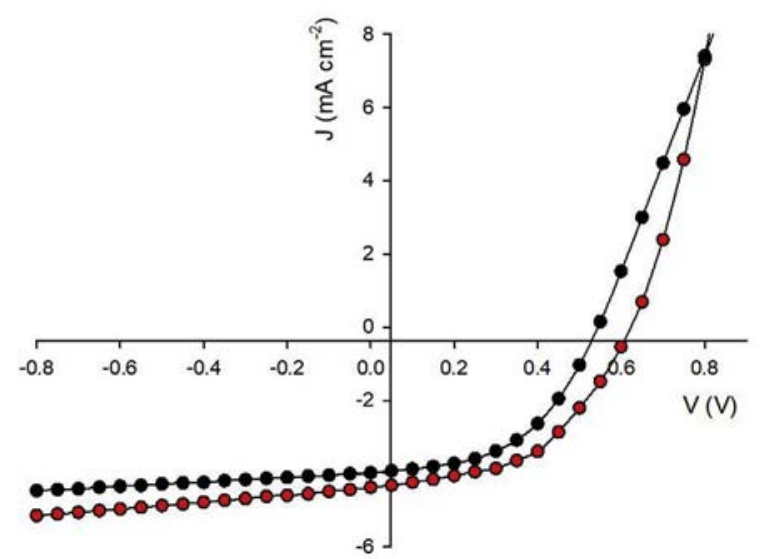

Fig. 5. Current density vs voltage curves for the best bilayer cells BDF1/C60 (black) and BDF2/C60 (red) after annealing at $190{ }^{\circ} \mathrm{C}$ and $180^{\circ} \mathrm{C}$ respectively. (For interpretation of the references to colour in this figure legend, the reader is referred to the Web version of this article.) 


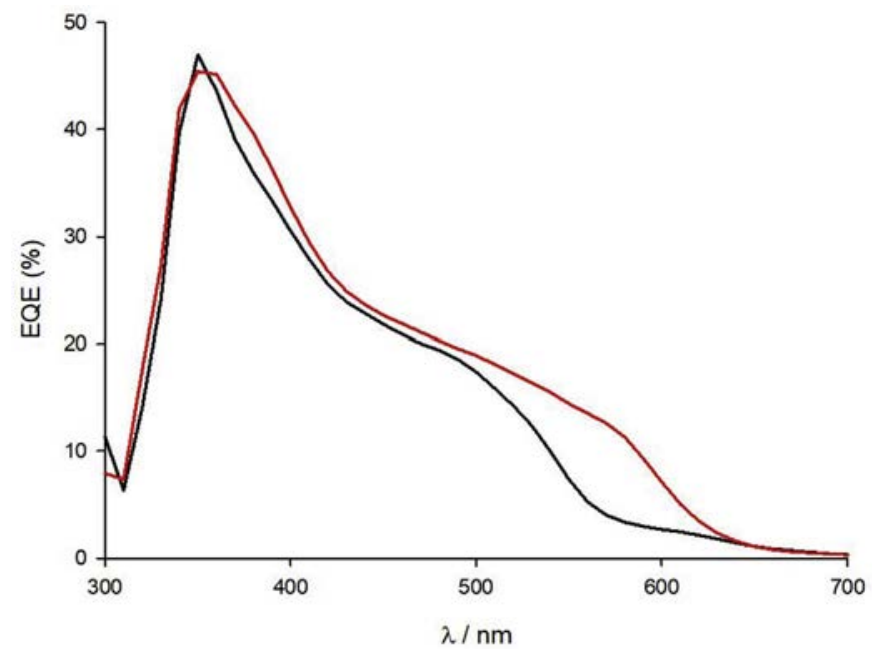

Fig. 6. External quantum efficiency (EQE) of the cells produced with donors BDF1 (black) and BDF2 (red). (For interpretation of the references to colour in this figure legend, the reader is referred to the Web version of this article.)

quantum yield efficiency (EQE) spectra for the best cells built with BDF1 and BDF2 were recorded under monochromatic irradiation (Fig. 6). Both spectra show a broad wave extending from 300 to 600 with a maximum at $380 \mathrm{~nm}$, probably corresponding in part to the contribution of $\mathrm{C}_{60}$ to the photocurrent, followed by a shoulder around $500 \mathrm{~nm}$ for BDF1 and $590 \mathrm{~nm}$ for BDF2 due to the donor derivatives.

\section{Conclusion}

In summary, two new extended TPA - benzodifuran derivatives connected by cyano-vinylene junctions have been synthesized. The synthetic approach to vehicle the cyanovinyl-BDF building block involves the diacetonitrile - BDF synthon, easily and rapidly prepared. The electronic property studies reveal a high electronic delocalization between the two external TPA units, through the central BDF moiety, allowing an easy access to the dication state. The new derivatives present optical properties and energy levels suitable for use as donor materials for photovoltaic conversion. The influence of the extension of the conjugated systems on the electronic properties with the insertion of the furan cycles shows a narrowing band gap, an increasing of quantum yield for the fluorescence and an enhancement of the photovoltaic characteristics. Conjugated polymers exploiting the new diACNBDF building block are now underway and will be reported in future publications.

\section{Acknowledgment}

The Région Pays de la Loire is acknowledged for financing the Green-SCO projects and a graduate scholarship for A. Faurie.

\section{Appendix A. Supplementary data}

Supplementary data related to this article can be found at http://dx. doi.org/10.1016/j.dyepig.2018.02.025.

\section{References}

[1] Gidron O, Bendikov M. $\alpha$-Oligofurans: an emerging class of conjugated oligomers for organic electronics. Angew Chem Int Ed 2014;53:2546-55.

[2] Cao H, Rupar PA. Recent advances in conjugated furans. Chem Eur J 2017;23:14670-5.

[3] Gidron O, Diskin-Posner Y, Bendikov M. alpha-Oligofurans. J Am Chem Soc 2010;132:2148-50.

[4] Bunz UHF. $\alpha$-Oligofurans: molecules without a twist. Angew Chem Int Ed 2010;49:5037-40.
[5] Gidron O, Varsano N, Shimon LJW, Leitus G, Bendikov M. Study of a bifuran vs. bithiophene unit for the rational design of pi-conjugated systems. what have we learned? Chem Commun 2013;49:6256-8.

[6] Jin X-H, Sheberla D, Shimon LJW, Bendikov M. Highly coplanar very long oligo (alkylfuran)s: a conjugated system with specific head-to-head defect. J Am Chem Soc 2014;136:2592-601.

[7] Vázquez RJ, Kim H, Kobilka BM, Hale BJ, Jeffries-El M, Zimmerman P, et al. Evaluating the effect of heteroatoms on the photophysical properties of donoracceptor conjugated polymers based on 2,6-Di(thiophen-2-yl)benzo[1,2-b:4,5-b'] difuran: two-photon cross-section and ultrafast time-resolved spectroscopy. J Phys Chem C 2017;121:14382-92.

[8] Gidron O, Dadvand A, Sheynin Y, Bendikov M, Perepichka DF. Towards "green" electronic materials. $\alpha$-Oligofurans as semiconductors. Chem Commun 2011;47:1976-8.

[9] Gidron O, Dadvand A, Wei-Hsin Sun E, Chung I, Shimon LJW, Bendikov M, et al. Oligofuran-containing molecules for organic electronics. J Mater Chem C 2013;1:4358-67.

[10] Mohakud S, Alex AP, Pati SK. Ambipolar charge transport in $\alpha$-Oligofurans: a theoretical study. J Phys Chem C 2010;114:20436-42.

[11] Du J, Bulumulla C, Mejia I, McCandless GT, Biewer MC, Stefan MC. Evaluation of (E)-1,2-di(furan-2-yl)ethene as building unit in diketopyrrolopyrrole alternating copolymers for transistors. Polym Chem 2017;8:6181-7.

[12] Woo CH, Beaujuge PM, Holcombe TW, Lee OP, Fréchet JMJ. Incorporation of Furan into low band-gap polymers for efficient solar cells. J Am Chem Soc 2010;132:15547-9.

[13] Bijleveld JC, Karsten BP, Mathijssen SGJ, Wienk MM, de Leeuw DM, Janssen RAJ. Small band gap copolymers based on furan and diketopyrrolopyrrole for field-effect transistors and photovoltaic cells. J Mater Chem 2011;21:1600-6.

[14] Yiu AT, Beaujuge PM, Lee OP, Woo CH, Toney MF, Fréchet JMJ. Side-chain tunability of Furan-containing low-band-gap polymers provides control of structural order in efficient solar cells. J Am Chem Soc 2012;134:2180-5.

[15] Sonar P, Singh SP, Williams EL, Li Y, Soh MS, Dodabalapur A. Furan containing diketopyrrolopyrrole copolymers: synthesis, characterization, organic field effect transistor performance and photovoltaic properties. J Mater Chem 2012;22:4425-35.

[16] Mallet C, Didane Y, Watanabe T, Yoshimoto N, Allain M, Videlot-Ackermann C, et al. Electronic properties and field-effect transistors of oligomers end-capped with benzofuran moieties. Chem Plus Chem. 2013;78:459-66.

[17] Mallet C, Moussallem C, Faurie A, Allain M, Gohier F, Skene WG, et al. Rational topological design for fluorescence enhancement upon aggregation of distyrylfuran derivatives. Chem Eur J 2015;21:7944-53.

[18] Faurie A, Mallet C, Allain M, Skene WG, Frère P. Topological and packing mode modification for solid-state emission enhancement of bis(perfluorostyryl)furan derivatives. New J Chem 2016;40:6728-34.

[19] Kazantsev MS, Frantseva ES, Kudriashova LG, Konstantinov VG, Mannanov AA, Rybalova TV, et al. Highly-emissive solution-grown furan/phenylene co-oligomer single crystals. RSC Adv 2016;6:92325-9.

[20] Zhao Z, Nie H, Ge C, Cai Y, Xiong Y, Qi J, et al. Furan is superior to thiophene: a furan-cored AIEgen with remarkable chromism and OLED performance. Adv Sci 2017;4. 1700005 .

[21] Koskin IP, Mostovich FA, Benassi E, Kazantsev MS. Way to highly emissive materials: increase of rigidity by introduction of a Furan moiety in co-oligomers. J Phys Chem C 2017;121:23359-69.

[22] Huang P, Du J, Biewer MC, Stefan MC. Developments of furan and benzodifuran semiconductors for organic photovoltaics. J Mater Chem A 2015;3:6244-57.

[23] Tsuji H, Mitsui C, Ilies L, Sato Y, Nakamura E. Synthesis and Properties of 2,3,6,7Tetraarylbenzo[1,2-b:4,5-b'] difurans as hole-transporting material. J Am Chem Soc 2007;129:11902-3.

[24] Tsuji H, Mitsui C, Sato Y, Nakamura E. Bis(carbazolyl)benzodifuran: a high-mobility ambipolar material for homojunction organic light-emitting diode devices. Adv Mater 2009;21:3776-9.

[25] Mitsui C, Tsuji H, Sato Y, Nakamura E. Carbazolyl benzo[1,2-b:4,5-b']difuran: an ambipolar host material for full-color organic light-emitting diodes. Chem Asian J 2012;7:1443-50.

[26] Bosiak MJ, Rakowiecki M, Orłowska KJ, Kędziera D, Adams J. Synthesis and photoluminescent properties of conjugated aryl-vinyl dioctyl 2,6-dimethylbenzofuro [5,6-b]furan-3,7-dicarboxylate derivatives. Dyes Pigments 2013;99:803-11.

[27] Bosiak MJ, Trzaska P, Kędziera D, Adams J. Synthesis and photoluminescence properties of star-shaped 2,3,6,7-tetrasubstituted benzo[1,2-b:4,5-b'] difurans. Dyes Pigments 2016;129:199-208.

[28] Bosiak MJ, Jakubowska JA, Aleksandrzak KB, Kamiński S, Kaczmarek-Kędziera A, Ziegler-Borowska M, et al. Synthesis of a new class of highly fluorescent aryl-vinyl benzo[1,2-b:4,5-b’] difuran derivatives. Tetrahedron Lett 2012;53:3923-6.

[29] Kobilka BM, Hale BJ, Ewan MD, Dubrovskiy AV, Nelson TL, Duzhko V, et al. Influence of heteroatoms on photovoltaic performance of donor-acceptor copolymers based on 2,6-di(thiophen-2-yl)benzo[1,2-b:4,5-b']difurans and diketopyrrolopyrrole. Polym Chem 2013;4:5329-36.

[30] Liu B, Qiu B, Chen X, Xiao L, Li Y, He Y, et al. High performance polymer solar cells based on a two dimensional conjugated polymer from alkylthienyl-substituted benzodifuran and benzothiadiazole. Polym Chem 2014;5:5002-8.

[31] Huo L, Liu T, Fan B, Zhao Z, Sun X, Wei D, et al. Organic Solar cells based on a 2D Benzo[1,2-b:4,5-b']difuran-conjugated polymer with high-power conversion efficiency. Adv Mater 2015;27:6969-75.

[32] Qiu B, Cui R, Yuan J, Peng H, Zhang Z, Li Y, et al. Synthesis and photovoltaic properties of two new alkoxylphenyl substituted thieno[2,3-f]benzofuran based polymers. Phys Chem Chem Phys 2015;17:17592-600. 
[33] Huang P, Du J, Gunathilake SS, Rainbolt EA, Murphy JW, Black KT, et al. Benzodifuran and benzodithiophene donor-acceptor polymers for bulk heterojunction solar cells. J Mater Chem A 2015;3:6980-9.

[34] Du J, Fortney A, Washington KE, Biewer MC, Kowalewski T, Stefan MC. Benzo[1,2b:4,5-b']difuran and furan substituted diketopyrrolopyrrole alternating copolymer for organic photovoltaics with high fill factor. J Mater Chem A 2017;5:15591-600.

[35] He D, Qiu L, Yuan J, Zhang Z-G, Li Y, Zou Y. Synthesis and photovoltaic properties of alkylthio phenyl substituted benzodifuran (BDF)-based conjugated polymers. Synth Met 2017;226:31-8.

[36] Bin H, Zhong L, Yang Y, Gao L, Huang H, Sun C, et al. Medium bandgap polymer donor based on bi(trialkylsilylthienyl-benzo[1,2-b:4,5-b']-difuran) for high performance nonfullerene polymer solar cells. Adv Energy Mater 2017;7. 1700746.

[37] Du Z, Chen Y, Chen W, Qiao S, Wen S, Liu Q, et al. Development of new twodimensional small molecules based on benzodifuran for efficient organic solar cells. Chem Asian J 2014;9:2621-7.

[38] Bian L, Hai J, Zhu E, Yu J, Liu Y, Zhou J, et al. A versatile strategy to directly synthesize 4,8-functionalized benzo[1,2-b:4,5-b[prime or minute]]difurans for organic electronics. J Mater Chem A 2015;3:1920-4.

[39] Huo L, Huang Y, Fan B, Guo X, Jing Y, Zhang M, et al. Synthesis of a 4,8-dialkoxybenzo[1,2-b:4,5-b']difuran unit and its application in photovoltaic polymer. Chem Commun 2012;48:3318-20.

[40] Huo L, Ye L, Wu Y, Li Z, Guo X, Zhang M, et al. Conjugated and nonconjugated substitution effect on photovoltaic properties of benzodifuran-based photovoltaic polymers. Macromolecules 2012;45:6923-9.

[41] Kobilka BM, Dubrovskiy AV, Ewan MD, Tomlinson AL, Larock RC, Chaudhary S, et al. Synthesis of 3,7-diiodo-2,6-di(thiophen-2-yl)benzo[1,2-b:4,5-b']difurans: functional building blocks for the design of new conjugated polymers. Chem Commun 2012;48:8919-21.

[42] Moussallem C, Gohier F, Mallet C, Allain M, Frère P. Extended benzodifuran - furan derivatives as example of pi-conjugated materials obtained from sustainable approach. Tetrahedron 2012;68:8617-21.
[43] Moussalem C, Segut O, Gohier F, Allain M, Frère P. Facile access via green procedures to a material with the benzodifuran moiety for organic photovoltaics. ACS Sustainable Chem Eng 2014;2:1043-8.

[44] Faurie A, Grolleau J, Gohier F, Allain M, Legoupy S, Frère P. Toward sustainable organic semiconductors from a broad palette of green reactions. Eur J Org Chem 2017:2707-14.

[45] Liu Q, Wang J, Li D, Yang C, Xia W. Photoinduced intermolecular [4+2] cycloaddition reaction for construction of benzobicyclo[2.2.2]octane skeletons. J Org Chem 2017;82:1389-402.

[46] Liu J, Wang K, Zhang X, Li C, You X. Triazine dyes as photosensitizers for dyesensitized solar cells. Tetrahedron 2013;69:190-200.

[47] Singla P, Van Steerteghem N, Kaur N, Ashar AZ, Kaur P, Clays K, et al. Multifunctional geometrical isomers of ferrocene-benzo[1,2-b:4,5-b']difuran-2,6$(3 \mathrm{H}, 7 \mathrm{H})$-dione adducts: second-order nonlinear optical behaviour and charge transport in thin film OFET devices. J Mater Chem C 2017;5:697-708.

[48] Wang K-P, Lei Y, Chen J-P, Ge Z-H, Liu W, Zhang Q, et al. The coumarin conjugate: synthesis, photophysical properties and the ratiometric fluorescence response to water content of organic solvent. Dyes Pigments 2018;151:233-7.

[49] Moussallem C, Gohier F, Frère P. Extended benzodifuran-thiophene systems connected with azomethine junctions: synthesis and electronic properties. Tetrahedron Lett 2015;56:5116-9.

[50] Cardona CM, Li W, Kaifer AE, Stockdale D, Bazan GC. Electrochemical considerations for determining absolute frontier orbital energy levels of conjugated polymers for solar cell applications. Adv Mater 2011;23:2367-71.

[51] Fang H-H, Chen Q-D, Yang J, Xia H, Gao B-R, Feng J, et al. Two-photon pumped amplified spontaneous emission from cyano-substituted Oligo(p-phenylenevinylene) crystals with aggregation-induced emission enhancement. J Phys Chem C 2010;114:11958-61.

[52] Gierschner J, Park SY. Luminescent distyrylbenzenes: tailoring molecular structure and crystalline morphology. J Mater Chem C 2013;1:5818-32. 